\title{
INDOOR / OUTDOOR PM LEVELS AND EC SURROGATE, AT TYPICAL MICROENVIRONMENTS IN THE ATHENS AREA
}

\author{
E. DIAPOULI* \\ A. CHALOULAKOU \\ N. SPYRELLIS ${ }^{\dagger}$
}

Received: 21/12/09

Accepted: 09/02/10

\author{
School of Chemical Engineering, \\ National Technical University of Athens \\ 9, Heroon Polytechnioy Street, Zographos Campus, \\ 15773 Athens, Greece
}

*to whom all correspondence should be addressed: e-mail: diapouli@mail.ntua.gr

\begin{abstract}
The aim of the present work was to characterize particulate matter (PM) and elemental carbon (EC) indoor and outdoor concentration levels in the Athens area and to examine the contribution of ambient air to the observed indoor levels.

24-hr simultaneous indoor and outdoor $\mathrm{PM}_{10}$ and $\mathrm{PM}_{2.5}$ measurements were conducted at a central (CR) and a suburban (SR) residence, and at an office in the commercial centre of Athens (CO), during cold and warm period of 2006. The absorption coefficient ( $\alpha$ ) was measured on the collected filters, as a surrogate for EC concentration levels.

Ambient PM levels were very high at both central sites and significant at SR (mean 24-hr $\mathrm{PM}_{10}$ : 87.4, 50.3 and $87.3 \mu \mathrm{g} \mathrm{m}^{-3}$ and $\mathrm{PM}_{2.5}: 50.7,20.2$ and $42.8 \mu \mathrm{g} \mathrm{m}^{-3}$ at $\mathrm{CR}, \mathrm{SR}$ and CO). The measured absorption coefficient values were very high at $\mathrm{CR}$ and $\mathrm{CO}$ for both size fractions.

Indoor PM concentration and absorption coefficient values were lower than the respective outdoor ones, but still significant at the two central sites.

Very good correlations were observed between indoor and outdoor data (especially for absorption coefficient values), indicating a large contribution of the ambient atmosphere to the indoor levels, more pronounced in finer particles.
\end{abstract}

KEYWORDS: Indoor / outdoor levels, $\mathrm{PM}_{10} / \mathrm{PM}_{2.5}$, Absorption coefficient, Elemental carbon, Indoor particles of outdoor origin.

\section{INTRODUCTION}

Numerous epidemiological studies have documented that current day levels of particulate matter (PM) air pollution are associated with adverse health effects, including increased risks of morbidity and mortality, mainly due to respiratory and cardio-vascular diseases (Pope and Dockery, 2006; Pope et al., 2002). Research interest is directed towards densely populated urban centres, where significant ambient PM concentrations have been observed. The main source of particulate air pollution in these areas is vehicular traffic. An important component of traffic-related PM is elemental carbon (EC). EC is the dominant light-absorbing substance in the atmosphere. It is composed primarily of carbon-based chemical by-products formed from incompletely combusted or un-combusted hydrocarbon-based fuels.

Event though epidemiological studies examine association of health effects with ambient concentration levels, the scientific interest has lately turned towards the indoor microenvironment. Urban populations spend about $90 \%$ of the time indoors, with the

${ }^{\dagger}$ Prof. Spyrellis suddenly passed away. We would like to dedicate this work to his memory. 
residence and work microenvironments being the prevailing ones according to the duration of occupancy (Adgate et al., 2002; Brauer et al., 2000). It has become apparent, thus, that indoor concentration levels may contribute significantly to total personal exposure, often exceeding the respective contribution of the ambient atmosphere. Therefore, associations between outdoor levels of air pollution and health outcomes may be plausible only if health relevant constituents of ambient air pollution efficiently penetrate indoors.

The aim of the present work was the characterization of $\mathrm{PM}\left(\mathrm{PM}_{10}\right.$ and $\left.\mathrm{PM}_{2.5}\right)$ and elemental carbon (EC) indoor and outdoor concentration levels in the Athens area, at two typical microenvironments: the residential and office microenvironment. Moreover, indoor and outdoor data were analyzed in order to examine the contribution of ambient air to the observed indoor levels.

\section{METHODS}

Two residences, one in a central area of Athens (CR) and one in a quite suburb (SR), as well as an office in the commercial centre of Athens (CO), were selected for study. Both CR and $\mathrm{CO}$ are located in high-trafficked and densely populated areas, while SR is located in a neighborhood characterized by low traffic, no commercial activity and many green areas. All measurements took place during cold and warm period of 2006. Each site was studied for at least two weeks and up to one month. The under-study rooms were a bedroom at CR and $\mathrm{SR}$, usually empty during the day, and a non-smoking office at $\mathrm{CO}$. The specific rooms were selected as to present minimum indoor particle generation, in order to reveal the impact of ambient air to indoor concentration levels.

Simultaneous 24-hr indoor and outdoor measurements of $\mathrm{PM}_{10}$ and $\mathrm{PM}_{2.5}$ mass concentration were conducted by the use of Harvard samplers, at a flow rate of 4 LPM. Both indoor and outdoor samplers were placed at a height of $1.0-1.5 \mathrm{~m}$ (breathing height). Indoor samplers were positioned in the centre of the under-study room, at some distance from walls and openings. Outdoor sampling took place at the terraces, outside the rooms.

The absorption coefficient $(\alpha)$ was measured on the collected $\mathrm{PM}_{10}$ and $\mathrm{PM}_{2.5}$ filters by the use of a smoke stain reflectometer (Model EEL 043 D, Diffusion Systems, Ltd). Numerous studies have indicated that there is an excellent correlation between coefficient $\alpha$ and concentration of particulate EC, suggesting thus that absorbance of PM filters may be used as a surrogate for elemental carbon concentration levels (Adams et al., 2002; Kinney et al., 2000; Edwards et al., 1983).

\section{RESULTS AND DISCUSSION Meteorological conditions}

Measurements were conducted during both cold and warm period. Cold period corresponded to the months November - April and warm period to the months May - October. Basic statistics for the daily values of main meteorological parameters are presented in Table 1.

Table 1. Basic statistics for the daily values of temperature $(T)$, relative humidity $(R H)$, wind speed (Ws) [mean \pm standard deviation] and rainfall (Rf) [total rainfall height (number of days with rainfall episode)], during the measurement period

\begin{tabular}{lcccc}
\hline & $\mathbf{T ~}\left({ }^{\circ} \mathbf{C}\right)$ & $\mathbf{R H}(\%)$ & $\mathbf{W s}\left(\mathbf{m ~ s}^{-1}\right)$ & $\mathbf{R f}(\mathbf{m m})$ \\
\hline Cold period & $12.0 \pm 3.2$ & $67.4 \pm 9.6$ & $1.5 \pm 0.9$ & $97.6(24)$ \\
Warm period & $20.0 \pm 3.2$ & $61.3 \pm 14.2$ & $2.3 \pm 1.4$ & $22.6(9)$ \\
\hline
\end{tabular}

\section{Outdoor measurements}

The measured PM levels were comparable for cold and warm period. Mean daily outdoor PM concentration levels are presented in Table 2.

Ambient levels were very high at both central sites and significant at the suburban residential area, with the mean values in all three sites surpassing the E.U. 24-hr air quality standard for $\mathrm{PM}_{10}\left(50 \mu \mathrm{g} \mathrm{m}^{-3}\right)$. The fraction of days that exceedance of the $24-\mathrm{hr}$ limit value was observed, was calculated equal to $84 \%$ for CR, $57 \%$ for SR and $100 \%$ for CO. Regarding $\mathrm{PM}_{2.5}$ 
concentration levels, at the two central sites mean concentrations were greater than $25 \mu \mathrm{g} \mathrm{m}^{-3}$, which is the E.U. annual limit value for this size fraction, to be achieved during $2010-2020$. If the measured concentrations are compared with the 24-hr limit value of $35 \mu \mathrm{g} \mathrm{m}^{-3}$, proposed by the C.A.F.E. working group (2004), exceedances were observed during $69 \%$ and $43 \%$ of the days at $\mathrm{CR}$ and $\mathrm{CO}$, respectively.

Table 2. Mean daily outdoor $\mathrm{PM}_{10}$ and $\mathrm{PM}_{2.5}$ concentration levels $\left[\mu \mathrm{g} \mathrm{m}^{-3}\right.$ ]

\begin{tabular}{lcccc}
\hline & \multicolumn{2}{c}{$\mathbf{P M}_{10}$} & \multicolumn{2}{c}{$\mathbf{P M}_{2.5}$} \\
\hline & Mean \pm St. Dev. & Range & Mean \pm St. Dev. & Range \\
\hline CR & $87.4 \pm 28.5$ & $37.2-134.7$ & $50.7 \pm 18.8$ & $29.8-80.3$ \\
SR & $50.3 \pm 9.1$ & $36.0-61.4$ & $20.2 \pm 5.7$ & $13.9-26.3$ \\
CO & $87.3 \pm 28.1$ & $55.9-161.1$ & $42.8 \pm 16.7$ & $25.3-87.4$ \\
\hline
\end{tabular}

The value of the $\mathrm{PM}_{2.5}$-to- $\mathrm{PM}_{10}$ concentration ratio reflected the main source affecting each site. Mean $\mathrm{PM}_{2.5} / \mathrm{PM}_{10}$ ratio was calculated equal to 0.72 and 0.70 at $\mathrm{CR}$ and $\mathrm{CO}$, indicating a strong contribution of vehicular traffic, which produces mainly fine particles. The corresponding ratio at SR was much lower (equal to 0.42), indicative of stronger coarse particle sources, which may be attributed to the free land and green areas surrounding the under-study site.

The measured absorption coefficient $(\alpha)$ was high at the two central sites (CR and CO). Coefficient $\alpha$ may be used as surrogate for particulate elemental carbon (EC) concentration. It is therefore expected to present significant values in areas with high vehicular traffic, which is considered the main EC source in urban areas (Janssen et al., 2001). Basic statistics for the absorbance measurements on the filters collected outdoors are presented in Table 3.

Table 3. Mean daily outdoor absorption coefficient $(\alpha)$ values measured in $\mathrm{PM}_{10}$ and $\mathrm{PM}_{2.5}$ filters $\left[10^{-5} \mathrm{~m}^{-1}\right]$

\begin{tabular}{ccccc}
\hline & $\boldsymbol{\alpha}\left(\mathbf{P M}_{\mathbf{1 0}}\right)$ & \multicolumn{2}{c}{$\boldsymbol{\alpha}\left(\mathbf{P M}_{\mathbf{2 . 5}}\right)$} \\
\hline & Mean \pm St. Dev. & Range & Mean \pm St. Dev. & Range \\
\hline CR & $5.9 \pm 2.8$ & $1.5-11.6$ & $4.2 \pm 1.7$ & $2.1-7.7$ \\
SR & $1.2 \pm 0.2$ & $0.8-1.6$ & $1.0 \pm 0.5$ & $0.5-1.8$ \\
CO & $4.2 \pm 2.2$ & $2.2-12.3$ & $3.7 \pm 1.5$ & $2.3-7.0$ \\
\hline
\end{tabular}

The measured absorption coefficient values for $\mathrm{PM}_{2.5}$ were similar to the ones reported in the literature. The respective mean daily values given in other studies, conducted in the city of Athens as well, are in the range $2.6 \cdot 10^{-5}-3.5 \cdot 10^{-5} \mathrm{~m}^{-1}$ (Puustinen et al., 2007; Lai et al., 2006; Gotschi et al., 2002). Similar levels to the ones measured at the two central sites (CR and $\mathrm{CO}$ ) have been also reported for Erfurt, Germany $\left(4.0 \cdot 10^{-5} \mathrm{~m}^{-1}\right)$ by Ruuskanen et al. (2001) and for Verona, Italy $\left(4.2 \cdot 10^{-5} \mathrm{~m}^{-1}\right)$ by Gotschi et al. (2005). These two studies present the highest values reported in the literature. The absorption coefficient values measured at the suburban site were compatible with the ones measured in other European cities, such as Helsinki, Finland, Oxford, U.K., Basel, Switzerland (Puustinen et al., 2007; Lai et al., 2006; Gotschi et al., 2002).

Relative results for $\mathrm{PM}_{10}$ are scarce. Fischer et al. (2000) reported $\mathrm{PM}_{10}$ absorption coefficient values for Amsterdam, Netherlands equal to $1.6 \cdot 10^{-5} \mathrm{~m}^{-1}$ (in a low-traffic site) and $3.0 \cdot 10^{-5} \mathrm{~m}^{-1}$ (in a heavy-traffic site). In another study in Huddersfield, U.K., the respective mean value was equal to $1.7 \cdot 10^{-5} \mathrm{~m}^{-1}$ (Kingham et al., 2000).

The absorption coefficient presented a very good correlation with mass concentration for both size fractions ( $r$ equal to 0.84 for $\mathrm{PM}_{10}$ and 0.80 for $\mathrm{PM}_{2.5}$ ). Elemental carbon is expected to correspond mainly to fine particles (with an aerodynamic diameter of less than $1 \mu \mathrm{m}$ ) (Seinfeld \& Pandis, 2006; Chow, 1995). Nevertheless, the high correlation coefficient between 
$\mathrm{PM}_{10}$ and the respective absorption coefficient values indicated that a significant portion may be found in coarse particles as well.

\section{Indoor measurements}

The measured mean daily indoor $\mathrm{PM}_{10}$ and $\mathrm{PM}_{2.5}$ concentration levels are presented in Table 4. Indoor $\mathrm{PM}_{10}$ and $\mathrm{PM}_{2.5}$ concentrations were lower than the respective outdoor ones at all three sites. Nevertheless, significant levels were observed in the two central sites for both PM fractions. The fraction of days that exceedance of the 24-hr limit value for ambient $\mathrm{PM}_{10}$ concentration was observed, was calculated equal to $58 \%$ for CR and $23 \%$ for CO. In SR there was no exceedance. Regarding $\mathrm{PM}_{2.5}$, concentration levels were greater than the 24-hr limit value of $35 \mu \mathrm{g} \mathrm{m}^{-3}$, proposed by the C.A.F.E. working group (2004), during $31 \%$ and $22 \%$ of the days at $\mathrm{CR}$ and $\mathrm{CO}$, respectively. Again, no exceedance was observed in SR.

Table 4. Mean daily indoor $\mathrm{PM}_{10}$ and $\mathrm{PM}_{2.5}$ concentration levels $\left[\mu \mathrm{g} \mathrm{m}^{-3}\right]$

\begin{tabular}{lcccc}
\hline & \multicolumn{2}{c}{$\mathbf{P M}_{\mathbf{1 0}}$} & \multicolumn{2}{c}{$\mathbf{P M}_{2.5}$} \\
\hline & Mean \pm St. Dev. & Range & Mean \pm St. Dev. & Range \\
\hline CR & $51.6 \pm 15.2$ & $24.9-79.4$ & $31.9 \pm 8.5$ & $22.0-47.7$ \\
SR & $20.5 \pm 4.2$ & $15.8-28.1$ & $16.6 \pm 3.6$ & $12.8-21.0$ \\
CO & $56.5 \pm 28.1$ & $28.6-185.5$ & $37.4 \pm 14.9$ & $24.3-83.2$ \\
\hline
\end{tabular}

The absorption coefficient values measured on the indoor filters were slightly lower than the respective outdoor values (Table 5). Nevertheless, again there was a significant difference between the values measured at central sites in relation to the suburban site, confirming that traffic-related air pollution may greatly affect the indoor microenvironments (Wichmann et al., 2005). The absorption coefficient values presented a good correlation with PM mass for both size fractions ( $r$ equal to 0.73 for $\mathrm{PM}_{10}$ and 0.83 for $\mathrm{PM}_{2.5}$ ).

Table 5. Mean daily indoor absorption coefficient $(\alpha)$ values measured in $\mathrm{PM}_{10}$ and $\mathrm{PM}_{2.5}$ filters $\left[10^{-5} \mathrm{~m}^{-1}\right]$

\begin{tabular}{ccccc}
\hline & $\boldsymbol{\alpha}\left(\mathbf{P M}_{\mathbf{1 0}}\right)$ & \multicolumn{2}{c}{$\boldsymbol{\alpha}\left(\mathbf{P M}_{\mathbf{2 . 5}}\right)$} \\
\hline & Mean \pm St. Dev. & Range & Mean \pm St. Dev. & Range \\
\hline CR & $4.9 \pm 2.5$ & $1.0-9.7$ & $3.1 \pm 1.7$ & $1.2-6.0$ \\
SR & $0.9 \pm 0.2$ & $0.7-1.2$ & $0.8 \pm 0.4$ & $0.4-1.4$ \\
CO & $3.8 \pm 1.8$ & $2.2-11.3$ & $3.3 \pm 1.3$ & $2.2-6.8$ \\
\hline
\end{tabular}

\section{Indoor - outdoor relationships}

Indoor-to-outdoor concentration $(\mathrm{I} / \mathrm{O})$ ratios were below 1.00 at all sites and during all measurement days, indicating that there was no significant indoor source (Table 6). Thus, indoor concentration levels were expected to be mainly affected by the ambient atmosphere.

Table 6. Mean daily $\mathrm{I} / \mathrm{O}$ ratios for $\mathrm{PM}_{10}$ and $\mathrm{PM}_{2.5}$

\begin{tabular}{ccccc}
\hline & \multicolumn{2}{c}{$\mathbf{P M}_{\mathbf{1 0}}$} & \multicolumn{2}{c}{$\mathbf{P M}_{\mathbf{2 . 5}}$} \\
\hline & Mean \pm St. Dev. & Range & Mean \pm St. Dev. & Range \\
\hline CR & $0.61 \pm 0.12$ & $0.40-0.90$ & $0.66 \pm 0.09$ & $0.50-0.83$ \\
SR & $0.42 \pm 0.14$ & $0.31-0.63$ & $0.84 \pm 0.07$ & $0.75-0.92$ \\
CO & $0.61 \pm 0.09$ & $0.47-0.82$ & $0.87 \pm 0.11$ & $0.64-0.99$ \\
\hline
\end{tabular}

Regression analysis of all indoor and outdoor concentration data was conducted in order to further support the above-mentioned assumption. The corresponding regressions for PM mass and particulate EC (absorption coefficient values) are presented in Figures $1 a, b$ and 2 $a, b$ respectively. 
In effect, the calculated correlation coefficients were significant. An excellent correlation was observed between indoor and outdoor absorption coefficient values $(r=0.98$ for both size fractions). This finding, along with slope values close to 1.00 (equal to 0.84 for $\mathrm{PM}_{10}$ and 0.90 for $\mathrm{PM}_{2.5}$ ) and low intercept values, clearly indicated that there was a large contribution of the ambient atmosphere to the indoor levels and that a large fraction of particulate EC of outdoor origin penetrated the indoor microenvironments (Halios et al., 2009; Na \& Cocker III, 2005; Geller et al., 2002; Gotchi et al., 2002).

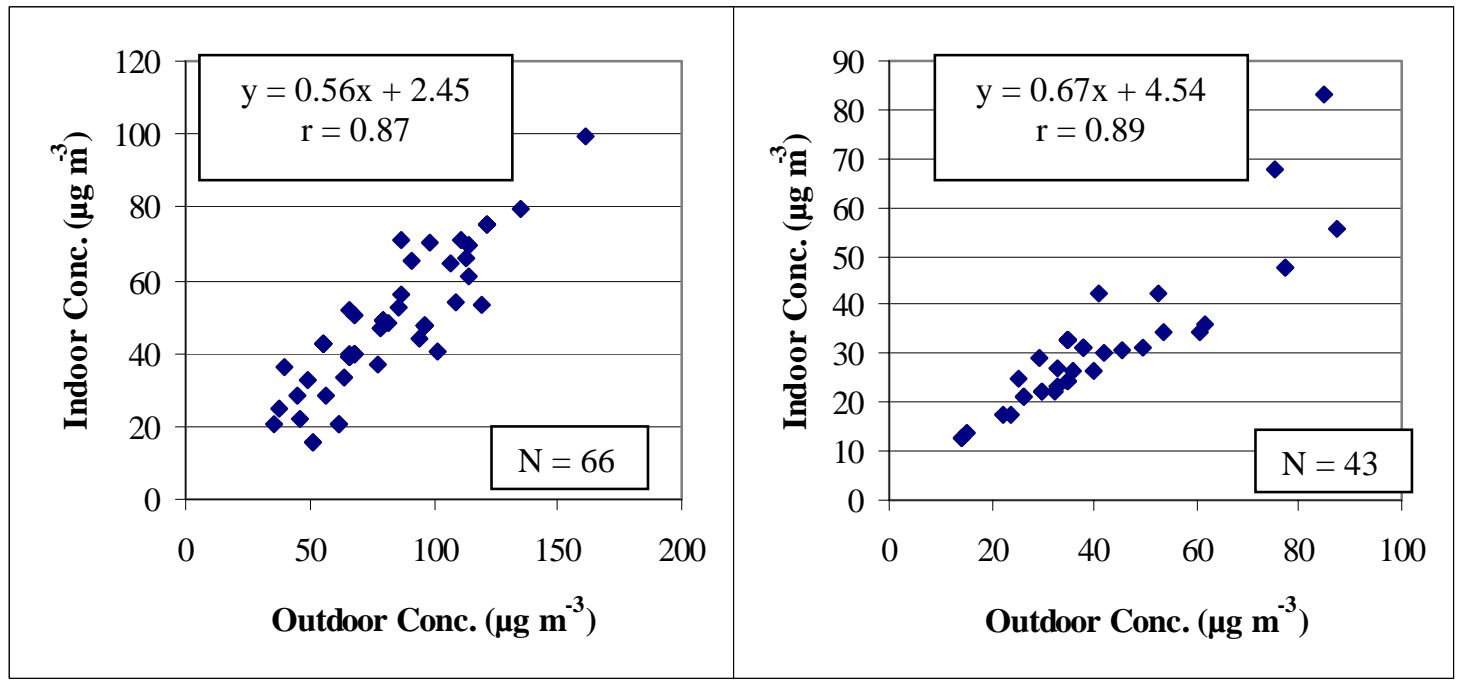

(a) (b)

Figure 1. Regression of indoor and outdoor concentrations for $\mathrm{PM}_{10}$ (a) and $\mathrm{PM}_{2.5}$ (b).

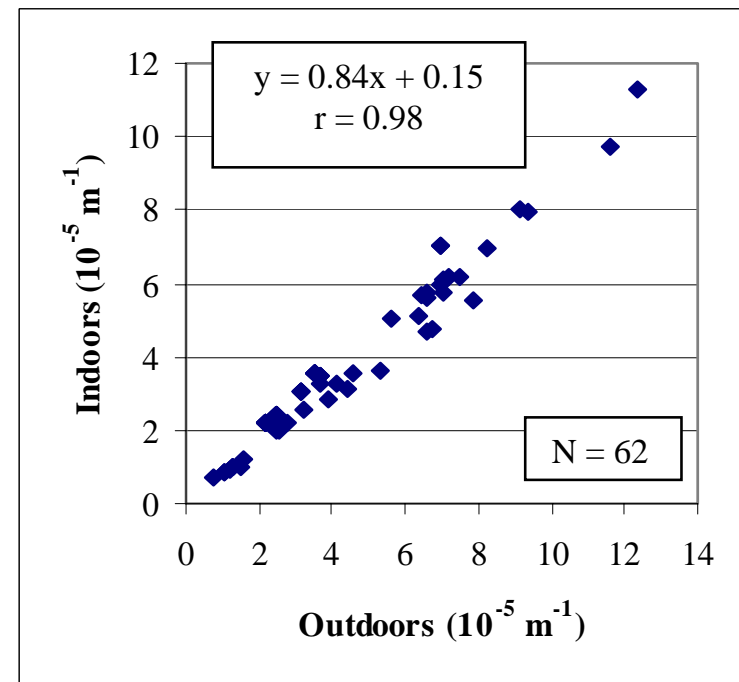

(a)

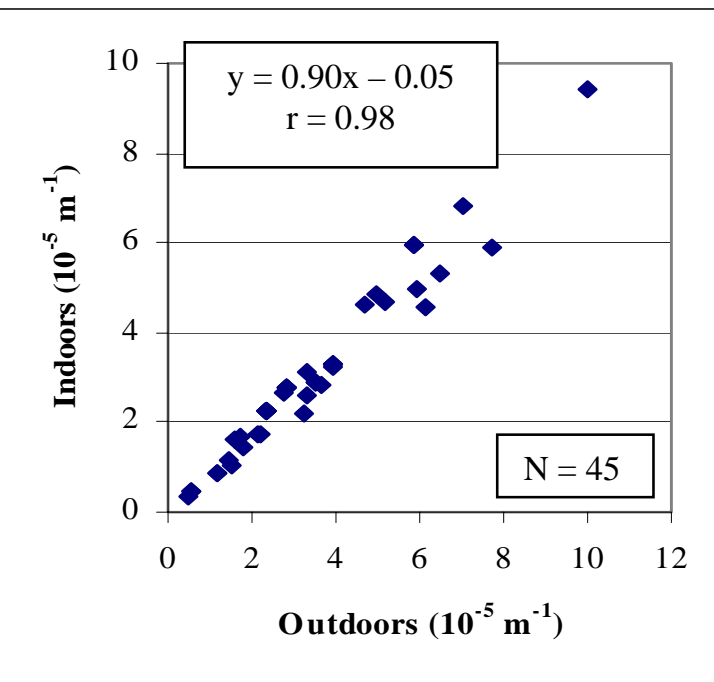

(b)

Figure 2. Regression of indoor and outdoor absorption coefficient values for $\mathrm{PM}_{10}(\mathrm{a})$ and $\mathrm{PM}_{2.5}$ (b)

The corresponding correlation coefficients for $\mathrm{PM}_{10}$ and $\mathrm{PM}_{2.5}$ concentration levels were calculated equal to 0.87 and 0.89 respectively, demonstrating again a significant contribution of the ambient atmosphere. The intercept values were again very low. The only important difference regarding the regression analysis results of absorbance and PM concentrations related to the slope values, which were much lower in the case of PM mass $\left(0.56\right.$ for $\mathrm{PM}_{10}$ and 0.67 for $\mathrm{PM}_{2.5}$ ). The significant impact of the ambient atmosphere to the residential concentration levels was also confirmed by the study of the indoor and outdoor concentrations diurnal cycles for CR, reported in a previous work (Diapouli et al., 2008). 
The regression analysis results confirm the differences in the behaviour of particles when entering an indoor microenvironment, in relation to their size distribution and their chemical composition. Particulate elemental carbon is a chemically stable component, which is mainly found in particles smaller than $1 \mu \mathrm{m}$ in aerodynamic diameter. It is therefore expected that it will penetrate indoors easier than larger particle fractions. Similarly, a higher fraction of ambient $\mathrm{PM}_{2.5}$ may penetrate indoors in comparison to $\mathrm{PM}_{10}$, which, due to their larger size, are obstructed when entering.

\section{CONCLUSIONS}

The aim of the present work was the characterization of $\mathrm{PM}\left(\mathrm{PM}_{10}\right.$ and $\left.\mathrm{PM}_{2.5}\right)$ and elemental carbon (EC) indoor and outdoor concentration levels in the Athens area, at two critical for personal exposure microenvironments: the residential and office microenvironment. Two residences, one in a central area and one in a quite suburban area, as well as one office in the commercial center of Athens, were studied. Indoor microenvironments were selected as to present minimum indoor particle generation, in order to reveal the impact of ambient air to indoor concentration levels, through the examination of indoor / outdoor data relationships.

The results showed very high ambient levels at both central sites and significant levels at the suburban residential area, with the mean values in all three sites surpassing the E.U. 24-hr air quality standard for $\mathrm{PM}_{10}\left(50 \mu \mathrm{g} \mathrm{m}^{-3}\right)$. Exceedance of the 24-hr limit value was observed for 84 and $100 \%$ of the measurement days at CR and CO respectively. Significant ambient concentrations were also recorded for $\mathrm{PM}_{2.5}$ at both central sites (mean concentrations were greater than $25 \mathrm{\mu g} \mathrm{m}^{-3}$, which is the E.U. annual limit value for this size fraction, to be achieved during $2010-2020$ ).

The measured absorption coefficient values at the two central sites were also high, in comparison to relative results presented in the international literature, indicating a large contribution of elemental carbon in PM mass.

The measured indoor concentration levels were lower than the outdoor ones, as expected since there was minimum activity in the indoor microenvironments. Nevertheless, the results indicated significant population exposure indoors. High concentration levels of both size fractions were observed in the two central sites. Exceedance of the 24-hr limit value for ambient $\mathrm{PM}_{10}$ concentration was observed during $58 \%$ and $23 \%$ of the days, at CR and CO respectively.

Absorption coefficient values for the indoor filters were slightly lower than the respective outdoor values. The influence of traffic-related air pollution to indoor air quality was clearly reflected by the significant difference between central and suburban site results.

The value of the correlation coefficient between indoor and outdoor data may be used as an indicator of the influence of ambient air to the concentration levels measured in an indoor microenvironment, for different PM species. According to the regression analysis of indoor and outdoor PM and EC surrogate data, a large fraction of the ambient PM pollution penetrated indoors causing elevated indoor concentration levels. This phenomenon was more pronounced in fine particles, which have been also proved to have greater potency to cause adverse health effects.

In view of the special role of the indoor microenvironment to total personal exposure, a thorough investigation of the parameters influencing indoor concentration levels is needed. Recent epidemiological studies have indicated that particles of indoor and outdoor origin may differ in their biological effects, due to their different sources, size distribution and chemical composition. The examination of indoor and outdoor data relationships for different PM constituents and size fractions may give an insight into population exposure in indoor microenvironments and the special role of outdoor PM sources. The final aim is a better understanding of the indoor and outdoor generated particles behaviour, which is crucial for population risk assessment, since it may enhance the development of effective mitigation measures and the implementation of specific practices that will lead to an integrated policy for the protection of public health. 


\section{REFERENCES}

1. Adams H.S., Nieuwenhuijsen M.J., Colvile R.N., Older M.J. and Kendall M. (2002), Assessment of Road Users' Elemental Carbon Personal Exposure Levels, London, UK, Atmospheric Environment, 36, 5335-5342.

2. Adgate J.L., Ramachandran G., Pratt G.C., Waller L.A. and Sexton K. (2002), Spatial and Temporal Variability in Outdoor, Indoor, and Personal $\mathrm{PM}_{2.5}$ Exposure, Atmospheric Environment, 36, 3255-3265.

3. Brauer M., Hruba F., Mihalikova E., Fabianova E., Miskovic P., Plzikova A., Lendacka M., Vandenberg J. and Cullen A. (2000), Personal Exposure to Particles in Banska Bystrica, Slovakia, Journal of Exposure Analysis and Environmental Epidemiology, 10, 478-487.

4. Chow J. (1995), Measurement Methods to Determine Compliance with Ambient Air Quality Standards for Suspended Particles, Journal of the Air and Waste Management Association, 45, 320-382.

5. Clean Air for Europe (C.A.F.E.) working group on particulate matter (2004), Second Position Paper on Particulate Matter.

6. Diapouli E., Chaloulakou A., Spyrellis N. (2008), Indoor and Outdoor PM Concentrations at a Residential Environment, in the Athens Area, Global NEST Journal, 10, 201-208.

7. Edwards J.D., Ogren J.A., Weiss R.E. and Charlson R.J. (1983), Particulate Air Pollutants: A Comparison of British «Smoke» with Optical Absorption Coefficient and Elemental Carbon Concentration, Atmospheric Environment, 17(11), 2337-2341.

8. Fischer P.H., Hoek G., van-Reeuwijk H., Briggs D.J., Lebret E., van-Wijnen J.H., Kingham S. and Elliott P.E. (2000), Traffic-Related Differences in Outdoor and Indoor Concentrations of Particles and Volatile Organic Compounds in Amsterdam, Atmospheric Environment, 34, 3713-3722.

9. Geller, M.D., Chang, M., Sioutas, C., Ostro, B.D. and Lipsett, M.J. (2002), Indoor/Outdoor Relationship and Chemical Composition of Fine and Coarse Particles in the Southern California Deserts, Atmospheric Environment, 36, 1099-1110.

10. Gotschi T., Hazenkamp-von-Arx M.E., Heinrich J., Bono R., Burney P., Forsberg B., Jarvis D., Maldonado J., Norback D., Stern W.B., Sunyer J., Toren K., Verlato G., Villani S. and Kunzli N. (2005), Elemental Composition and Reflectance of Ambient Fine Particles at 21 European Locations, Atmospheric Environment, 39, 5947-5958.

11. Gotschi T., Oglesby L., Mathys P., Monn C., Manalis N., Koistinen K., Jantunen M., Hanninen O., Polanska L. and Kunzli N. (2002), Comparison of Black Smoke and $\mathrm{PM}_{2.5}$ Levels in Indoor and Outdoor Environments of four European Cities, Environmental Science and Technology, 36, 1191-1197.

12. Halios C.C., Helmis C.G., Eleftheriadis K., Flocas H.A., Assimakopoulos V.D. (2009), A Comparative Study of the Main Mechanisms Controlling Indoor Air Pollution in Residential Flats, Water, Air and Soil Pollution, 204, 333-350.

13. Janssen N.A.H., van-Kliet P.H.N., Aarts, F., Harssema H. and Brunekreef B. (2001), Assessment of Exposure to Traffic Related Air Pollution of Children Attending Schools near Motorways, Atmospheric Environment, 35, 3875-3884.

14. Kingham S., Briggs D., Elliott, P., Fischer P. and Lebret E. (2000), Spatial Variations in the Concentrations of Traffic-Related Pollutants in Indoor and Outdoor Air in Huddersfield, England, Atmospheric Environment, 34, 905-916.

15. Kinney P.L., Aggarwal M., Northridge M.E., Janssen N.A.H. and Shepard P. (2000), Airborne Concentrations of $\mathrm{PM}_{2.5}$ and Diesel Exhaust Particles on Harlem Sidewalks: A CommunityBased Pilot Study, Environmental Health Perspectives, 108, 213-218.

16. Lai H.K., Bayer-Oglesby L., Colvile R., Gotschi T., Jantunen M.J., Kunzli N., Kulinskaya E., Schweizer C. and Nieuwenhuijsen M.J. (2006), Determinants of Indoor Air Concentrations of $\mathrm{PM}_{2.5}$, Black Smoke and $\mathrm{NO}_{2}$ in Six European Cities (EXPOLIS Study), Atmospheric Environment, 40, 1299-1313.

17. Na K., David R., Cocker III D.R. (2005), Organic and Elemental Carbon Concentrations in Fine Particulate Matter in Residences, Schoolrooms, and Outdoor Air in Mira Loma, California, Atmospheric Environment, 39, 3325-3333.

18. Pope C.A. and Dockery D.W. (2006), Health Effects of Fine Particulate Air Pollution: Lines that Connect, Journal of the Air and Waste Management Association, 56, 709-742. 
19. Pope C.A., Burnett R.T., Thun M.J., Calle E.E., Krewski D., Ito K. and Thurston G.D. (2002), Lung Cancer, Cardiopulmonary Mortality, and Long-term Exposure to Fine Particulate Air Pollution, Journal of the American Medical Association, 287(9), 1132-1141.

20. Puustinen A., Hameri K., Pekkanen J., Kulmala M., de-Hartog, J., Meliefste K., ten-Brink H., Kos G., Katsouyanni K., Karakatsani A., Kotronarou A., Kavouras I., Meddings C., Thomas S., Harrison R., Ayres J.G., van-der-Zee S. and Hoek G. (2007), Spatial Variation of Particle Number and Mass over four European Cities, Atmospheric Environment, 41, 6622-6636.

21. Ruuskanen J., Tuch Th., Ten-Brink T., Peters A., Khlystov A., Mirme A., Kos G.P.A., Brunekreef B., Wichmann H.E., Buzorius G., Vallius M., Kreyling W.G. and Pekkanen J. (2001), Concentrations of Ultrafine, Fine and $\mathrm{PM}_{2.5}$ Particles in three European Cities, Atmospheric Environment, 35(21), 3729-3738.

22. Seinfeld J.H. and Pandis S.N. (2006), Atmospheric Chemistry and Physics - From Air Pollution to Climate Change, Second Edition, John Wiley \& Sons, Inc., New Jersey.

23. Wichmann J., Janssen N.A.H., van-der-Zee S. and Brunekreef B. (2005), Traffic-related Differences in Indoor and Personal Absorption Coefficient Measurements in Amsterdam, the Netherlands, Atmospheric Environment, 39, 7384-7392. 